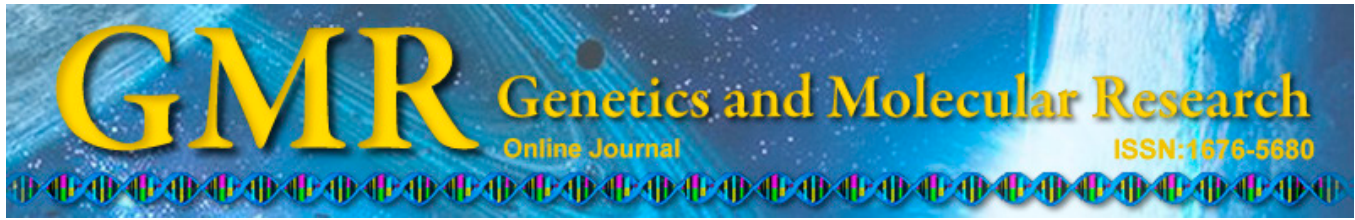

\title{
Polymorphisms in the methylene tetrahydrofolate reductase and methionine synthase reductase genes and their correlation with unexplained recurrent spontaneous abortion susceptibility
}

L. Zhu

Department of Gynecology, Woman \& Infants Hospital of Zhengzhou, Zhengzhou City, China

Corresponding author: L. Zhu

E-mail: zhuli_zzl@126.com

Genet. Mol. Res. 14 (3): 8500-8508 (2015)

Received January 8, 2015

Accepted May 14, 2015

Published July 28, 2015

DOI http://dx.doi.org/10.4238/2015.July.28.19

\begin{abstract}
We aimed to explore the correlation between unexplained recurrent spontaneous abortion and polymorphisms in the methylene tetrahydrofolate reductase (MTHFR) and methionine synthase reductase (MTRR) genes. A case control study was conducted in 118 patients with unexplained recurrent spontaneous abortion (abortion group) and 174 healthy women (control group). The genetic material was extracted from the oral mucosal epithelial cells obtained from all subjects. The samples were subjected to fluorescence quantitative PCR to detect the single nucleotide polymorphisms (SNPs) in the MTHFR (C677T and A1298C) and MTRR (A66G) gene loci. The distribution frequency (18/118, $15.3 \%$ ) of the MTHFR 677TT genotype was significantly higher in the abortion group $\left(\chi^{2}=11.006, P=0.004\right)$ than in the control group $(2 / 174$, $1.1 \%$ ); on the other hand, the distribution frequency of the MTHFR A1298C genotype did not significantly differ between the abortion and control groups $\left(\chi^{2}=0.441, \mathrm{P}=0.507\right)$. The distribution frequency of the MTRR A66G genotype was also significantly higher in the abortion group $\left(14 / 118,11.9 \% ; \chi^{2}=10.503, \mathrm{P}=0.005\right)$ than in the control group
\end{abstract}


(8/174, 4.6\%). The MTHFR C677T and MTRR A66G polymorphisms are significantly correlated with the occurrence of spontaneous abortion.

Key words: Recurrent miscarriages; Methylene tetrahydrofolate reductase; Methionine synthase reductase; Single nucleotide polymorphism

\section{INTRODUCTION}

Recurrent miscarriages refer to spontaneous abortions that occur $\geq 2$ times in a row. Recurrent miscarriages have been observed to occur at a rate of 1-2\% (Wilczynski et al., 2012) in the population. The disease etiology is extremely complex. Excluding the chromosomal, anatomical, endocrine, infectious, and autoantibody factors, there remain approximately $50 \%$ clinical patients whose etiology remains to be elucidated. These cases have been classified as unexplained recurrent spontaneous abortion (URSA) (Liu, 2013) cases. In this study, fluorescence quantitative PCR was used to identify all single nucleotide polymorphisms in the methylene tetrahydrofolate reductase (MTHFR) (C677T and A1298C) and methionine synthase reductase $(M T R R)(\mathrm{A} 66 \mathrm{G})$ gene loci; in addition, we attempted to determine the correlation between these polymorphisms and the occurrence of URSA.

\section{MATERIAL AND METHODS}

\section{Patient selection and exclusion criteria}

One hundred and eighteen patients with unexplained recurrent abortion admitted to the outpatient ward of the MCH Gynecology Department between January 2012 and May 2014 were included as the study group (abortion group). The following exclusion criteria were applied for the selection of patients: the presence of congenital malformations or tumors in the reproductive system, endocrine dysfunction, and chromosomal abnormalities in both parents (couples). The normal group (control group) was composed of 174 patients with normal pregnancies. All subjects were Han Chinese and unrelated to each other. This research study was approved by the Ethics Committee of $\mathrm{MCH}$. Informed consent was obtained from all participating patients.

\section{DNA sample collection}

Specimens were collected by trained dental practitioners. Oral mucosal epithelial cells were extracted using special sampling equipment; the specimens were collected by scraping up and down (for a minimum of) 40 times on one side of the mouth (the scraping apparatus was tilted up, as recommended). DNA samples were extracted from the cell samples using column extraction kits (Sangoo, Shanghai, China).

\section{Genetic testing}

The Taqman-MGB technology was used to detect single nucleotide polymorphisms in the MTHFR (C677T and A1298C) and MTRR (A66G) gene loci. All related instruments and reagents were obtained from Applied Biosystems (Waltham, MA, USA). 
The three gene loci were subjected to fluorescence quantitative PCR. The TaqmanMGB probe information is summarized in Table 1. PCR was conducted in a total reaction volume of $10 \mu \mathrm{L}$; this was composed of the $1 \mu \mathrm{L} 20 \mathrm{ng} / \mu \mathrm{L}$ DNA template, $5 \mu \mathrm{L} 2 \mathrm{X}$ Taqman Universal Master Mix, $0.5 \mu \mathrm{L} 20 \mathrm{X}$ Taqman-MGB probe, and $3.5 \mu \mathrm{L}$ deionized water. The reaction conditions were set as follows: initial denaturation at $95^{\circ} \mathrm{C}$ for $10 \mathrm{~min}$, followed by 20 cycles of amplification at $92^{\circ} \mathrm{C}$ for $15 \mathrm{~s}$ and $60^{\circ} \mathrm{C} 1 \mathrm{~min}$, an additional 30 cycles of amplification at $89^{\circ} \mathrm{C}$ for $15 \mathrm{~s}$ and $60^{\circ} \mathrm{C}$ or $1.5 \mathrm{~min}$, and a final extension at $72^{\circ} \mathrm{C}$ for $10 \mathrm{~min}$. The PCR products were separated by $1.8 \%$ agarose gel electrophoresis; the gel image was analyzed using the.

Partial PCR products (specific for the genetic loci of interest) were selected, purified, and sequenced.

\begin{tabular}{|c|c|c|c|}
\hline \multicolumn{2}{|c|}{ Probe } & \multicolumn{2}{|c|}{ Primers } \\
\hline MTHFR C677T-V2 & MTHFR C677T-M2 & MTHFR C677T-F & MTHFR C677T-R \\
\hline AATCGGCTCCCGC & AATCGACTCCCGC & GAAAAGCTGCGTGATG ATG & TTGAAGGAGAAGGTGTA \\
\hline MTHFR A1298C-V2 & MTHFR A1298C-M2 & MTHFR A1298C-F & MTHFR A1298C-R \\
\hline ACACTTGCTTCACT & ACACTTTCTTCACT & AAGAACGAAGACTTCAAA & TGGGGGGAGCTGAC \\
\hline MTRR A66G-V2 & MTRR A66G-M2 & MTRR A66G-F & MTRR A66G-R \\
\hline AAGAAATATGTGAG & AAGAAATGTGTGAG & AGGCAAAGGCCATCGCA & ATCCATGTACCACAGCTT \\
\hline
\end{tabular}

\section{Statistical data processing}

All statistical analyses were performed using the SPSS v.18.0 software platform (IBM, Armonk, NY, USA). The count date was analyzed using the chi-squared test. P values $<0.05$ were considered to be statistically significant.

\section{RESULTS}

\section{General characteristics of the study population and genetic equilibrium testing}

The research group was comprised of 118 patients who showed URSA; the patients were aged between 22 and 44 years, with a mean age of $29.8 \pm 4.3$ years. The control group consisted of 174 members, aged between 21 and 24 years, with a mean age of $28.5 \pm 4.0$ years. The age difference between the two groups was not statistically significant $(\mathrm{P}>0.05)$. The distribution frequencies of the MTHFR and MTRR gene loci in the two groups were analyzed using the $\chi^{2}$ test. The $\chi^{2}$ values of the MTHFR and MTRR gene loci in the URSA group were 0.42 and 0.18 , while the $\mathrm{P}$ values were 0.52 and 0.67 , respectively. The frequency of distribution of the MTHFR and MTRR gene loci in the control group was defined by $\chi^{2}$ values of 3.18 and 0.06 , with $P$ values of 0.07 and 0.80 , respectively. This indicated that the genotype distribution of the gene loci of interest in these two groups was consistent with the Hardy-Weinberg equilibrium.

\section{Polymorphisms in the C677T locus in the MTHFR gene}

The C667T site in the MTHFR gene could express polymorphisms with three genotypes: CC, CT, and TT. The PCR product of the CC genotype expressed the BseL1 endonucle- 
ase recognition site; therefore, this product formed two bands, 252- and 30-bp long, upon digestion. The occurrence of mutations in this locus would result in its non-recognition by the endonuclease enzyme; therefore, only a fragment of the 282-bp fragment was observed in the TT-type digested products. The CT genotype, on the other hand, formed three bands of 282, 252 , and $30 \mathrm{bp}$. The 30-bp band could not be observed in the agarose gel because of its small molecular weight (Figure 1). Among the 118 patients in the URSA group, 60 and 40 subjects displayed the $\mathrm{CC}$ and $\mathrm{CT}$ genotypes, respectively; on the other hand, among the 174 cases in the control group, 100, 72, and 2 subjects displayed the CC, CT, and TT genotypes, respectively (Figure 2a and b).

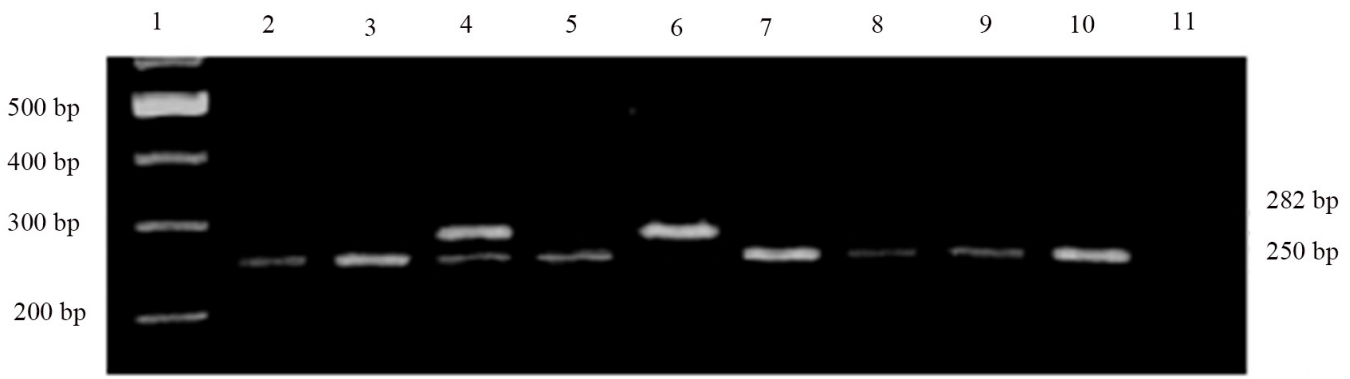

Figure 1. Results of electrophoresis of the digested C677T MTHFR gene products. Lane $1=100$-bp DNA marker; lanes 2, 3, 5, 7, 8, 9, and $10=$ PCR products with the CC genotype; lanes 4 and $11=$ PCR products with the CT genotype; lane $6=$ bands shown by the TT genotype.
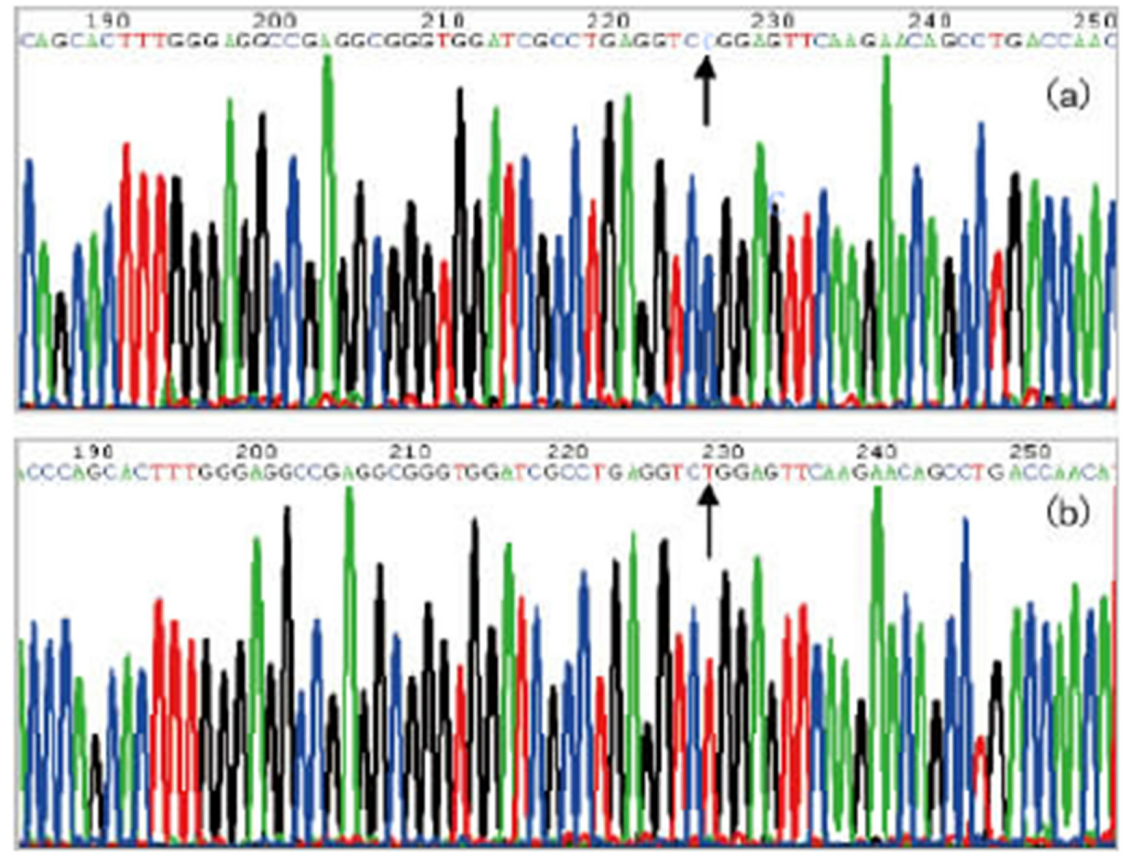

Figure 2. Sequence of the C667T locus in the MTHFR gene. a. Allele C, b. allele T. 


\section{Polymorphisms in the A1298C locus in the MTHFR gene}

The alleles $\mathrm{A}$ and $\mathrm{C}$ were wild-type and mutant alleles, respectively. The PCR products subjected to agarose gel electrophoresis were believed to be heterozygous (AC) when the alleles $\mathrm{A}$ and $\mathrm{C}$ were observed simultaneously, wide-type homozygous (AA) when only the allele A was observed, and mutant homozygous (CC) when only the allele $\mathrm{C}$ was observed (Figure 3). According to the results of this study, 48 and 58 patients of the URSA group and 76 and 88 patients in the control group demonstrated the AA and AC genotypes, respectively. None of the patients in both groups showed the CC genotype (Figure 4a and b).

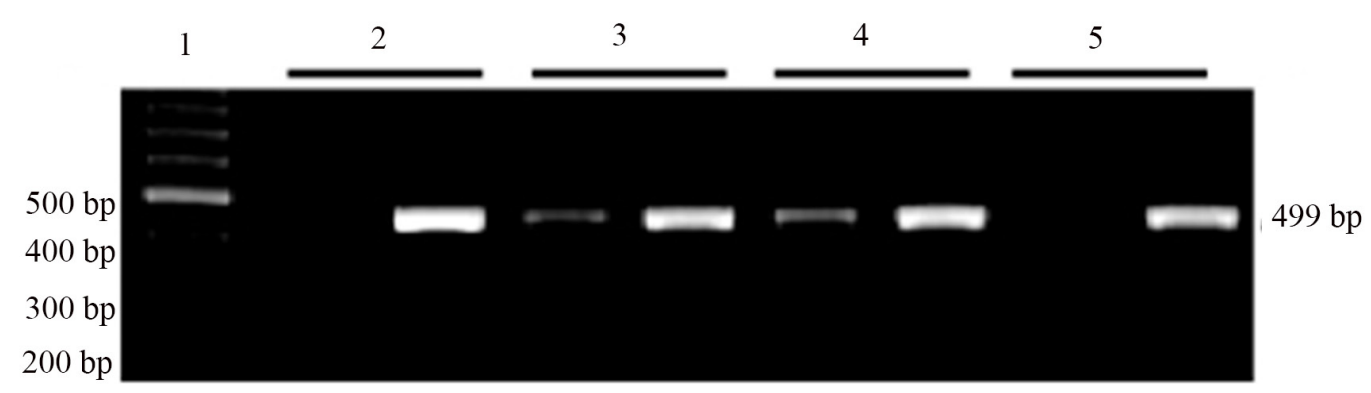

Figure 3. Results of electrophoresis of the AS-PCR amplified A1298C MTHFR gene products. Lane $1=100-\mathrm{bp}$ DNA marker; lanes 2 and $5=$ PCR products with the AA genotype; lanes 3 and $4=$ bands shown by the PCR products with the AC genotype.

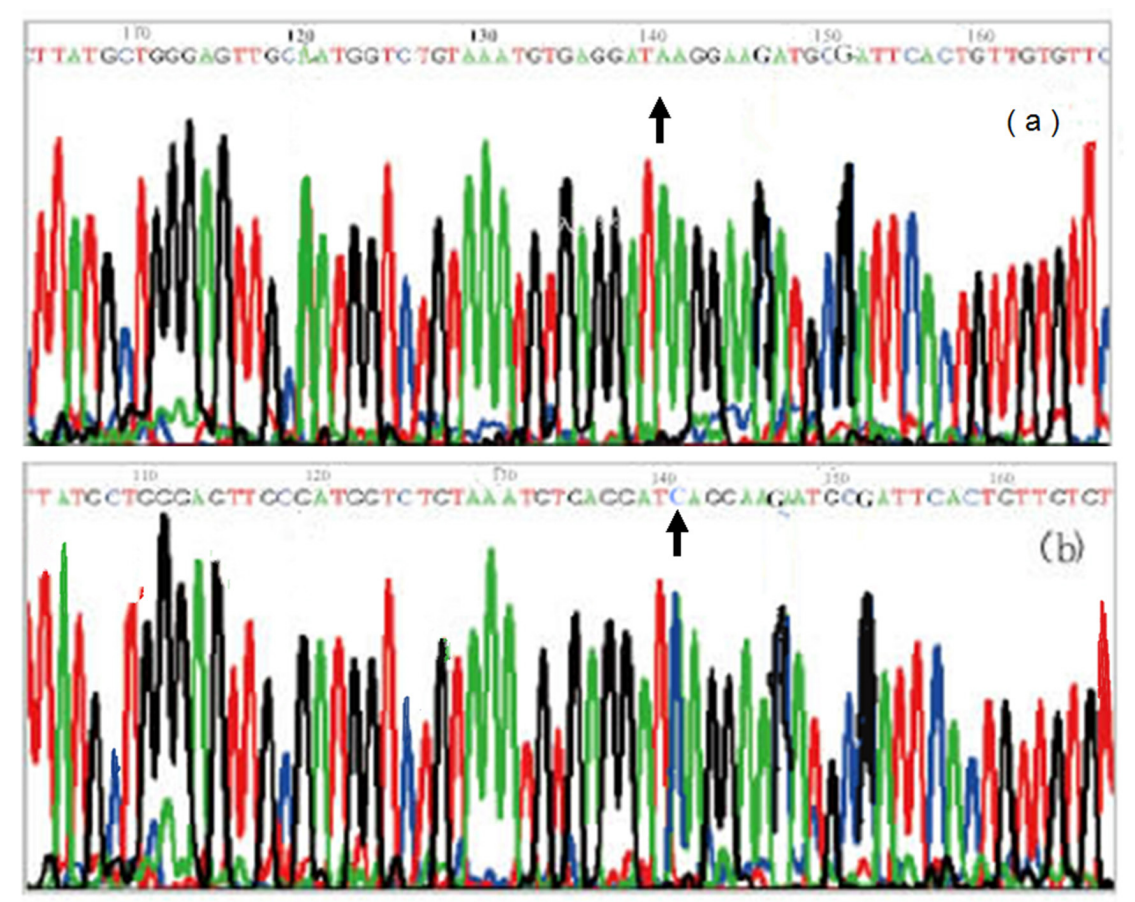

Figure 4. Sequence of the A1298C locus in the MTHFR gene. a. Allele A, b. allele C. 


\section{Polymorphisms in the A66G locus in the MTRR gene}

Polymorphisms in this locus could render 3 genotypes: AA, AG, and GG. Among the 118 and 153 patients classified into the URSA and control groups, 56 and 48 displayed the AA genotype, while 48 and 38 subjects showed the AG genotype; 8 subjects in the control group also showed the GG genotype (Figures 5 and $6 a$ and $b$ ).

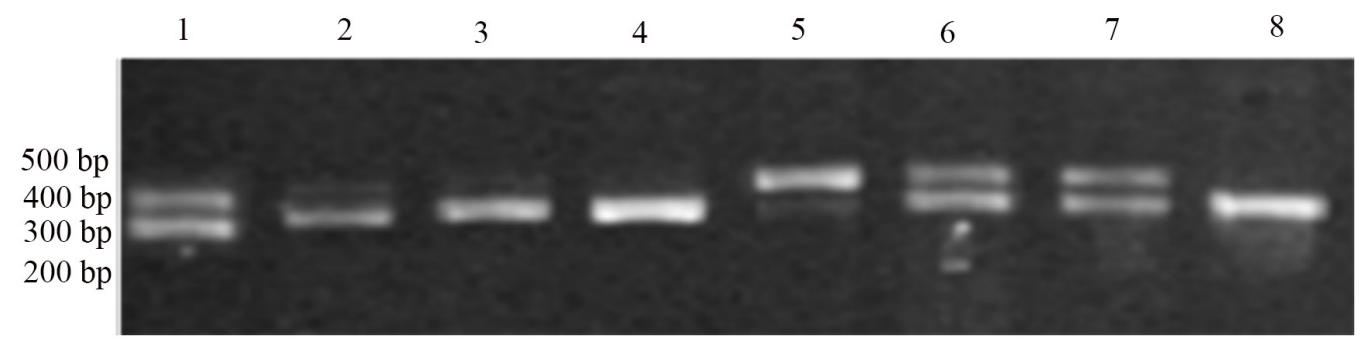

Figure 5. Results of electrophoresis of the AS-PCR amplified A66G MTRR gene products. Lane 1=100-bp DNA marker; lanes 2, 3, 5, 7, 8,9, and $10=$ bands shown by the PCR products with the CC genotype; lanes 4 and $11=$ bands shown by the CT genotype; and lane $6=$ PCR products with the TT genotype.

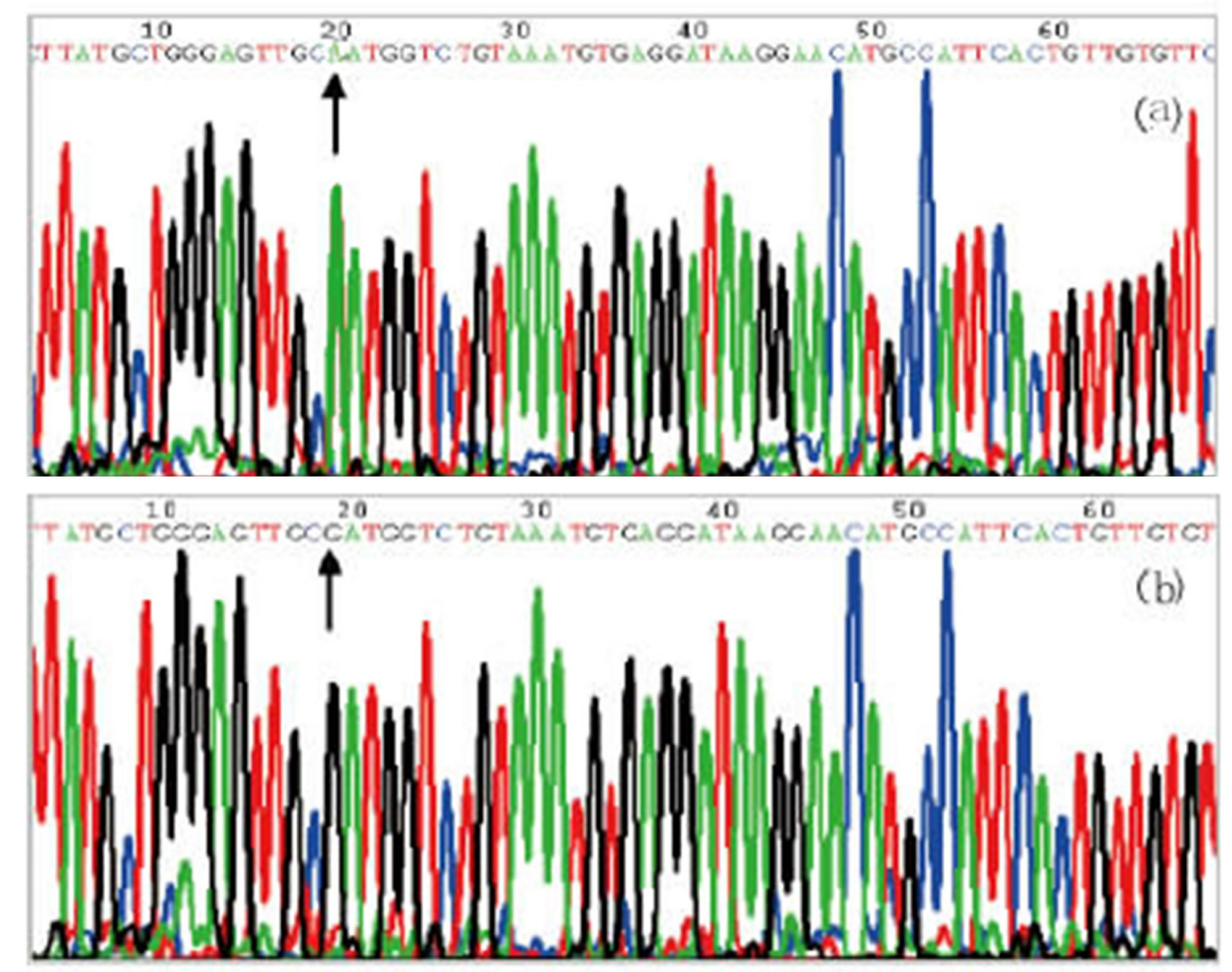

Figure 6. Sequence of the A66G locus in the $M T R R$ gene. a. Allele A, b. allele G. 


\section{Analysis of the genotype and allele frequencies}

\section{Distribution of the C677T genotype and allele frequencies in the MTHFR gene}

The distribution frequency of the C677T genotype in the MTHFR gene (15.3\%) was significantly higher in the abortion group than in the control group (1.1\%) (Table 2). This difference was observed to be statistically significant $\left(\chi^{2}=11.006, \mathrm{P}=0.004\right)$. The C677T allele frequency $(32.2 \%)$ in the MTHFR gene in the abortion group was significantly higher than that $(21.8 \%)$ observed in the control group $\left(\chi^{2}=3.923, \mathrm{P}=0.048\right)$.

\begin{tabular}{|c|c|c|c|c|c|c|}
\hline \multirow[t]{2}{*}{ Group } & \multirow[t]{2}{*}{$\mathrm{N}$} & \multicolumn{3}{|c|}{ Genotype frequency } & \multicolumn{2}{|c|}{ Allele frequency } \\
\hline & & $\mathrm{CC}$ & CT & TT & $\mathrm{C}$ & $\mathrm{T}$ \\
\hline Abortion group & 118 & $60(50.8)$ & $40(33.9)$ & $18(15.3)$ & $160(67.8)$ & $76(32.2)$ \\
\hline Control group & 174 & $100(57.5)$ & $72(41.4)$ & $2(1.1)$ & $272(78.2)$ & $76(21.8)$ \\
\hline$\chi^{2}$ & & \multirow{2}{*}{\multicolumn{3}{|c|}{11.006}} & \multirow{2}{*}{\multicolumn{2}{|c|}{3.923}} \\
\hline P value & & & & & & \\
\hline
\end{tabular}

\section{Distribution of the A1289C genotype and allele frequencies in the MTHFR gene}

The genotype $\left(\chi^{2}=1.001, \mathrm{P}=0.606\right)$ and allele $\left(\chi^{2}=0.441, \mathrm{P}=0.507\right)$ frequencies of the A1298C genotype in the MTHFR gene did not significantly differ between the abortion and control groups (Table 3 ).

\begin{tabular}{|c|c|c|c|c|c|c|}
\hline \multirow[t]{2}{*}{ Group } & \multirow[t]{2}{*}{$\mathrm{N}$} & \multicolumn{3}{|c|}{ Genotype frequency } & \multicolumn{2}{|c|}{ Allele frequency } \\
\hline & & AA & $\mathrm{AC}$ & $\mathrm{CC}$ & A & $\mathrm{C}$ \\
\hline Abortion group & 118 & $48(40.7)$ & $58(49.1)$ & $12(10.2)$ & $154(65.3)$ & $82(34.7)$ \\
\hline Control group & 174 & $76(43.7)$ & $88(50.6)$ & $10(5.7)$ & \multicolumn{2}{|c|}{$108(31.0)$} \\
\hline & & \multicolumn{3}{|c|}{1.001} & \multirow{2}{*}{\multicolumn{2}{|c|}{0.507}} \\
\hline P value & & \multicolumn{3}{|c|}{0.606} & & \\
\hline
\end{tabular}

\section{Distribution of the A66G genotype and allele frequencies in the MTRR gene}

The frequency of the 66GG genotype frequency was significantly higher in the MTRR genes of the patients in the abortion group (15.3\%) than that in the control patients $(4.6 \%)$; this difference was observed to be statistically significant $\left(\chi^{2}=10.503, \mathrm{P}=0.005\right)$. The frequency of the MTRR 66GG allele was also significantly higher in the abortion group $(32.2 \%)$ than that in the control group (15.5\%). This difference was also determined to be statistically significant $\left(\chi^{2}=11.313, \mathrm{P}=0.001\right)($ Table 4$)$. 
Table 4. Comparison of the genotype and allele frequencies of the C66T locus in the MTRR gene between the women of the abortion and control groups [N (\%)].

\begin{tabular}{llcccccc}
\hline Group & $\mathrm{N}$ & \multicolumn{3}{c}{ Genotype frequency } & & \multicolumn{2}{c}{ Allele frequency } \\
\cline { 3 - 5 } \cline { 3 - 4 } & & $\mathrm{AA}$ & $\mathrm{AG}$ & $\mathrm{GG}$ & & $\mathrm{A}$ & $\mathrm{G}$ \\
\hline Abortion group & 118 & $56(47.4)$ & $48(40.7)$ & $14(11.9)$ & & $160(67.8)$ & $76(32.2)$ \\
Control group & 174 & $128(73.6)$ & $38(2.8)$ & $8(4.6)$ & & $294(84.5)$ & $54(15.5)$ \\
$\chi^{2}$ & & 10.503 & & & & 11.313 & \\
P value & & & 0.005 & & & 0.001 & \\
\hline
\end{tabular}

\section{DISCUSSION}

Current research into the pathogenesis of URSA is concerned with identifying the changes in coagulation mechanism. Acquired and hereditary coagulation are two of the starting factors effecting a change in the coagulation mechanism (Adelberg and Kuller, 2002). Hereditary coagulation is closely related to genetic polymorphism. High homocysteinemia (homocysteine, hcy), which is induced by abnormalities in key enzymes (MTHFR and MTRR) regulating the folate metabolism, is an important factor causing blood hypercoagulation, and is an independent risk factor for several arterial and venous thrombus diseases (Isotalo et al., 2000; van der Molen et al., 2000; Candito et al., 2003). Hcy reacts with the methyl group released by 5 -methyl-tetrahydrofolate, in the presence of methionine synthase and vitamin B12 coenzyme, to generate methionine. 5,10-methylenete-tetrahydrofolate is reduced to 5-methyltetrahydrofolate in the presence of the MTHFR enzyme. The methylation of vitamin B12 is catalyzed by MTRR to maintain the activity of coenzyme, to ensure normal methionine synthase catalytic activity.

The MTHFR and MTRR are known to undergo multiple genetic polymorphisms. Currently, the C677T and A1298C polymorphisms in the MTHFR gene and the A66G polymorphism in the MTRR gene are the most studied polymorphism worldwide. These genetic polymorphisms affect the activity of the encoding enzymes (Candito et al., 2003), the concentration of serum and folate in the red blood cells (Eskes, 1998), and the Hcy levels in the plasma (Nishio et al., 2008). The 19.3-kb MTHFR gene is located in chromosome 1p36.3, and contains 12 exons. The transcripted mRNA is 7105 bp in length; the C677T polymorphism, located at the 5th exon, causes an amino acid change from Ala to Val, leading to a decrease in enzyme activity and thermal stability. The enzyme activity of the TT genotype has been observed to decrease to $22 \%$ of the normal, compared to the $677 \mathrm{CC}$ genotype. The A1298C polymorphism, on the other hand, located at the 8th exon, causes an amino acid change from Glu to Ala, also resulting in a decrease in enzyme activity (Jacques et al., 1996). The 32,021bp MTRR gene is located at chromosome 5p15.3-p15.2, and contains 15 exons. The A66G polymorphism, located at the 2nd exon, causes an amino acid change from Ile to Met.

This experiment analyzed the distribution frequencies of the polymorphisms in the MTHFR (C677T and A1298C) and MTRR (A66G) genes in women in the abortion and normal groups. The distribution frequency of the MTHFR 677TT polymorphism was significantly higher in the abortion group $(18 / 118,15.3 \%)\left(\chi^{2}=11.006, \mathrm{P}=0.004\right)$ than in the control group $(2 / 176,1.1 \%)$, while the difference in the various genotype frequencies in the MTHFR A1298 locus between the abortion and control groups was not statistically significant $\left(\chi^{2}=0.441, \mathrm{P}=\right.$ 0.507). The distribution frequency of MTRR A66G was also significantly higher in the abor- 
tion group $(14 / 118,11.9 \%)\left(\chi^{2}=10.503, \mathrm{P}=0.005\right)$ than in the control group $(8 / 176,4.6 \%)$. This showed that the MTHFR C677T and MTRR A66G polymorphisms were correlated with the incidence of spontaneous abortion; this is significant, as it would aid in monitoring the folate supplementation during pregnancy, thereby possibly reducing the rate of spontaneous abortion.

\section{Conflicts of interest}

The authors declare no conflict of interest.

\section{REFERENCES}

Adelberg AM and Kuller JA (2002). Thrombophilias and recurrent miscarriage. Obest. Gynecol. Surv. 57: 703-709.

Candito M, Magnaldo S, Bayle J, Dor JF, et al. (2003). Clinical B12 deficiency in one case of recurrent spontaneous pregnancy loss. Clin. Chem. Lab. Med. 41: 1026-1027.

Eskes TK (1998). Open or closed? A world of difference: a history of homo-cysteine research. Nutr. Rev. 56: 236-244.

Isotalo PA, Wells GA and Donnelly JG (2000). Neonatal and fetal methylene tetrahydrofolate reductase genetic polyorphisms: an examination of C677T and A1298C mutations. Am. J. Hum. Genet. 67: 986-990.

Jacques PF, Bostom AG, Williams RR, Ellison RC, et al. (1996). Relation between folate status, a common mutation in methylenetetrahydrofolate reductase, and plasma homocysteine concentrations. Circulation 93: 7-9.

Liu S (2013). Studies on the etiology of recurrent spontaneous abortion. J. China Modern Med. 20: 20

Nishio K, Goto Y, Kondo T, Ito S, et al. (2008). Serum folate and methylene tetrahydrofolate reductase (MTHFR) C677T polymorphism adjusted for folate intake. J. Epidemiol. 18:125-131.

van der Molen EF, Arends GE, Nelen WL, van der Puts NJ, et al. (2000). A common mutation in the 5,10-methylene tetrahydrofolate reductase gene as a new risk factor for placental vasculopathy. Am. J. Obstet. Gynecol. 182: 1258-1263.

Wilczynski JR, Radwan P, Tchorzewski H and Banasik M (2012). Immunotherapy of patients with recurrent spontaneous miscarriage and idiopathic infertility: does the immunization-dependent Th2 cytokine overbalance really matter? Arch. Immunol. Ther. Exp. 60: 151-160. 